\title{
Appendiceal Mucocele in an Elderly Patient: How Much Surgery?
}

\author{
C. Kim-Fuchs ${ }^{\mathrm{a}} \quad$ Y. Chittazhathu Kurian Kuruvilla ${ }^{\mathrm{a}} \quad$ E. Angst ${ }^{\mathrm{a}}$ \\ $\begin{array}{lll}\text { R. Weimann } & \text { B. Gloor } & \text { D. Candinas } \\ & \end{array}$
}

${ }^{a}$ Department of Visceral Surgery and Medicine, Inselspital, and ${ }^{\mathrm{b}}$ Institute of Pathology, University of Bern, Bern, Switzerland

\section{Key Words}

Mucocele · Appendix · Synchronous tumor - Mucinous cystadenocarcinoma

\begin{abstract}
Appendiceal mucoceles are rare cystic lesions with an incidence of $0.3-0.7 \%$ of all appendectomies. They are divided into four subgroups according to their histology. Even though the symptoms may vary - depending on the level of complication - from right lower quadrant pain, signs of intussusception, gastrointestinal bleeding to an acute abdomen with sepsis, most mucoceles are asymptomatic and found incidentally. We present the case of a 70-year-old patient with an incidentally found appendiceal mucocele. He was seen at the hospital for backache. The CT scan showed a vertebral fracture and a $7-\mathrm{cm}$ appendiceal mass. A preoperative colonoscopy displayed several synchronous adenomas in the transverse and left colon with high-grade dysplasia. In order to lower the cancer risk of this patient, we performed a subtotal colectomy. The appendiceal mass showed no histopathological evidence of malignancy and no sign of perforation. The follow-up was therefore limited to 2 months. In this case, appendectomy would have been sufficient to treat the mucocele alone. The synchronous high-grade dysplastic adenomas were detected in the preoperative colonoscopy and determined the therapeutic approach. Generally, in the presence of positive lymph nodes, a right colectomy is the treatment of choice. In the histological presence of mucinous peritoneal carcinomatosis, cytoreductive surgery with hyperthermic intraperitoneal chemotherapy is indicated. In conclusion, mucoceles of the appendix are detected with high sensitivity by CT scan. If there is no evidence of synchronous tumor preoperatively and no peritoneal spillage, invasion or positive sentinel lymph nodes during surgery, a mucocele is adequately treated by appendectomy.
\end{abstract}




\section{Introduction}

Most intestinal tumors are malignant and are treated by surgical resection potentially combined with neoadjuvant or adjuvant therapy [1-3]. There are different histological types of malignant and benign tumors of the small and large intestine. The variety includes polyps with varying grades of dysplasia, typical adenocarcinomas of the large and rarely the small intestine, rare leiomyomas and sarcomas commonly found in the small intestine, lymphomas, well to poorly differentiated neuroendocrine tumors and very rare appendiceal mucoceles ranging from benign to highly malignant diseases $[4,5]$. The term appendiceal mucocele was first described by Rokitanski [6] in 1842 and refers to a dilatation of the appendiceal lumen by an abnormal accumulation of mucus. This is a typical finding for the appendix, which is lined by an epithelium containing more goblet cells than the colon. Due to this mucus-producing epithelium, the majority of the epithelial tumors of the appendix are mucinous and start as mucoceles [7]. According to the classification introduced by the World Health Organization, mucoceles are classified into four histologic subgroups: simple retention cysts, mucosal hyperplasia, mucinous cystadenoma and mucinous cystadenocarcinoma [8]. Each subgroup is characterized by the presence or absence of mucus, hyperplasia, grade of the dysplastic features, atypical mucinous epithelium and peritoneal carcinomatosis, presenting as pseudomyxoma peritonei. The clinical course, the surgical treatment and the prognosis of appendiceal mucoceles relate to their histologic subtype. The prognosis ranges from excellent to poor. The cases with pseudomyxoma peritonei show a very poor outcome; therefore, an aggressive treatment is required. The clinical manifestation and laboratory findings are unspecific and several diseases are associated with structural changes in the ileocecal region. These include common acute appendicitis, inflammatory bowel diseases, rare infections (e.g. tuberculosis, actinomycosis) and tumors [9]. Young patients may be recommended for appendectomy assuming appendicitis. In case of the macroscopic aspect of a mucocele, the surgeon should be able to make the right decisions during surgery. In older patients it is more probable that imaging is performed before surgery. In this context, the computer tomography is highly sensitive to detect the mucocele as well as pseudomyxoma peritonei [10]. Older patients with high comorbidity need to be accurately diagnosed before surgery to evaluate their potential risks. Especially other synchronous tumors should be investigated. Furthermore, the question of 'how much surgery is recommendable for an older patient', is important. We therefore need a wise decision-making algorithm to reduce cancer risk while minimizing the risk of technical complications.

We herewith present the case of a 70-year-old patient with an incidentally found appendiceal mucocele combined with several high-grade dysplastic adenomas throughout the colon.

\section{Case Report}

A 70-year-old patient was seen at the hospital for backache. His medical history included alcohol abuse with consecutive encephalopathy, cognitive deficiency, liver cirrhosis with portal hypertension and recurrent falls. Furthermore, we found coronary cardiopathy, chronic renal insufficiency, insulin-dependent diabetes mellitus and generalized arteriosclerosis. CT scan showed a vertebral fracture and a $7-\mathrm{cm}$ mucocele of the appendix. It was a cystic tumor with intramural calcification and inhomogeneous uptake of contrast medium (fig. 1). To decide whether right colectomy was necessary, we performed colonoscopy. No pathology was revealed in the cecum, but several polyps were removed 
in the transverse and left colon. These corresponded to adenomas with high-grade dysplasia in the histologic examination. Because of the cancer risk of high-grade dysplastic adenomas, the patient underwent a subtotal colectomy comprising the appendiceal tumor as well. During surgery a $7-\mathrm{cm}$ nodulated white mass in the region of the appendix, plump and firm, fully flexible and covered with serosa, was completely resected. There were no signs of invasion of the periappendiceal soft tissue or the cecal wall and no mucinous deposits were present in the abdomen (fig. 2). To avoid rupture of the mucocele, we performed a thorough appendectomy first, then a near-total colectomy with ileosigmoidostomy. The pathological assessment showed a $6.8 \times 12 \mathrm{~cm}$ tumor attached to the normal appendix. The lumen of the appendix was massively dilated and filled with gelatinous material. Histologically, the diagnosis of a mucocele of the appendix with intramural dystrophic mineralization was made (fig. 3 ). There was no perforation and no evidence of a mucinous cystadenocarcinoma. The postoperative course was marked by comorbidities including alcoholic delirium, pneumonia, and transient worsening of the renal and the cardiac function. The patient's recovery was uneventful.

\section{Discussion}

Mucoceles of the appendix with the histopathological morphology of a retention cyst are adequately treated by appendectomy. In this reported case, colectomy was indicated to remove the adenomas with high-grade dysplasia.

Mucoceles of the appendix are rare cystic lesions characterized by a distended appendiceal lumen filled with mucus with an incidence of $0.3-0.7 \%$ of all appendectomies [11-13]. They can be subdivided according to their histopathological morphology into four subgroups: retention cysts (18\%), mucosal hyperplasia (20\%), mucinous cystadenoma (52\%) and mucinous cystadenocarcinoma (10\%) [8]. The clinical signs of appendiceal mucoceles are unspecific or absent. Therefore, detection occurs mostly incidentally by radiologic, sonographic or endoscopic intervention. Clinical signs include abdominal pain in the right lower quadrant, a palpable mass in slim patients, colicky pain in case of obstruction or intussusception, gastrointestinal bleeding and anemia, genitourinary symptoms, or acute abdomen and sepsis in case of a spontaneous rupture of the cyst $[12,14-15]$. In blood tests, the carcinoembryonic antigen may be elevated in neoplastic mucoceles: this indicator is therefore used in follow-up after surgical resection [16]. CT scan is the best diagnostic test for preoperative planning of the resection. It has a $93 \%$ overall sensitivity to detect rupture of the mucocele, peritoneal mucinous carcinomatosis or pseudomyxoma peritonei and wall calcification [17]. The diagnostic finding of a mucocele does not predict malignancy by itself. A colonoscopy may help in the distinction of benign and malignant lesions, but often mucosal biopsies are normal [15]. In general, the appendix is not accessible for investigation by endoscopy. But endoscopy shows synchronous tumors of the colon in $13 \%$ of the patients [13]. This was the case in our patient, where the adenomas with high-grade dysplasia led to an extended colonic resection.

Examination of the appendix during surgery cannot tell whether the tumor is benign or malignant [18]. Perforation of the wall of the mucocele may result in pseudomyxoma peritonei with the potential of spread of malignant tumor cells in the abdominal cavity. Therefore, trauma or rupture of the tumor has to be avoided at all costs, even at the price of conversion from laparoscopy to open surgery [19]. The peritoneal surfaces surrounding the appendix, the liver and the pelvis must be inspected for tumorous deposits or mucus. If detected, a sample should be sent for histopathologic or cytologic examination. Generally, mucinous tumors of the appendix spread through the wall of the appendix into the intraperitoneal cavity and rarely metastasize to the lymph nodes 
$[7,20]$. On this account a less aggressive surgical approach than right colectomy has been suggested: tumors confined to the appendix without evidence of peritoneal carcinomatosis or pseudomyxoma peritonei are resected with the retrocecal appendiceal lymph nodes and sent for frozen section. If these sentinel lymph nodes are negative, prophylactic right colectomy is not necessary and appendectomy is oncologically correct. If the resection is possible without perforation of the tumor, it may be done by laparoscopy, otherwise open surgery is mandatory. If the lymph nodes are positive, a right colectomy should be performed [20]. In our case colectomy was required because of the adenomas with high-grade dysplastic polyps, so lymph-node sampling was not necessary. In case of peritoneal carcinomatosis or pseudomyxoma peritonei, the above-mentioned treatment should be completed by peritonectomy and hyperthermic intraperitoneal chemotherapy [7].

Microscopically, retention cysts are lined by flat epithelium, dystrophic mineralization, fibrosis and mucus in the lumen of the cyst. Mucosal hyperplasia is characterized by additional hyperplastic epithelium, a mucinous cystadenoma by cellular atypia, glandular and papillary proliferation. Mucinous cystadenocarcinoma is characterized by invasion, local spread or peritoneal spilling [8].

For long-term prognosis, perforation of the tumor and leakage of mucus into the peritoneal cavity adversely affects prognosis. Low-grade mucinous neoplasms confined to the appendix behave as benign disease with $100 \%$ five-year survival, whereas the same tumors with extra-appendiceal spread show a much worse outcome of only $45 \%$ survival after 5 years [18]. Therefore, benign tumors without perforation do not need a follow-up. In case of perforation of the appendix without evident mucus during the primary surgery, tomography 6-monthly for 5 years is recommended. If a peritoneal carcinomatosis with atypical epithelial cells in the abdominal cavity is proved histologically, second-look cytoreductive surgery with hyperthermic intraperitoneal chemotherapy is indicated [7]. In our case without histological evidence of malignancy or peritoneal spread of the tumor, we refrained from further controls after the regular 2 months follow-up.

\section{Conclusion}

Mucoceles of the appendix are detected with high sensitivity by CT scan. A preoperative colonoscopy excludes synchronous tumors of the colon. If no extra-appendiceal spread or mucus is present during surgery and intraoperative nodal sampling is negative, a mucocele is adequately treated by appendectomy. Breaching of the tumor should be avoided.

\section{Acknowledgement}

We thank the Novartis Foundation for the generous financial support of the postdoctoral work of E. Angst. 


\begin{tabular}{r|l|l|l}
$\begin{array}{r}\text { Case Reports in } \\
\text { Gastroenterology }\end{array}$ & $\begin{array}{l}\text { Case Rep Gastroenterol 2011;5:516-522 } \\
\text { DOl: 10.1159/000331438 }\end{array}$ & $\begin{array}{l}\text { Published online: } \\
\text { September 3, 2011 }\end{array}$ & $\begin{array}{l}\text { I 2011 S. Karger AG, Basel } \\
\text { ISSN 1662-0631 } \\
\text { www.karger.com/crg }\end{array}$ \\
\hline
\end{tabular}
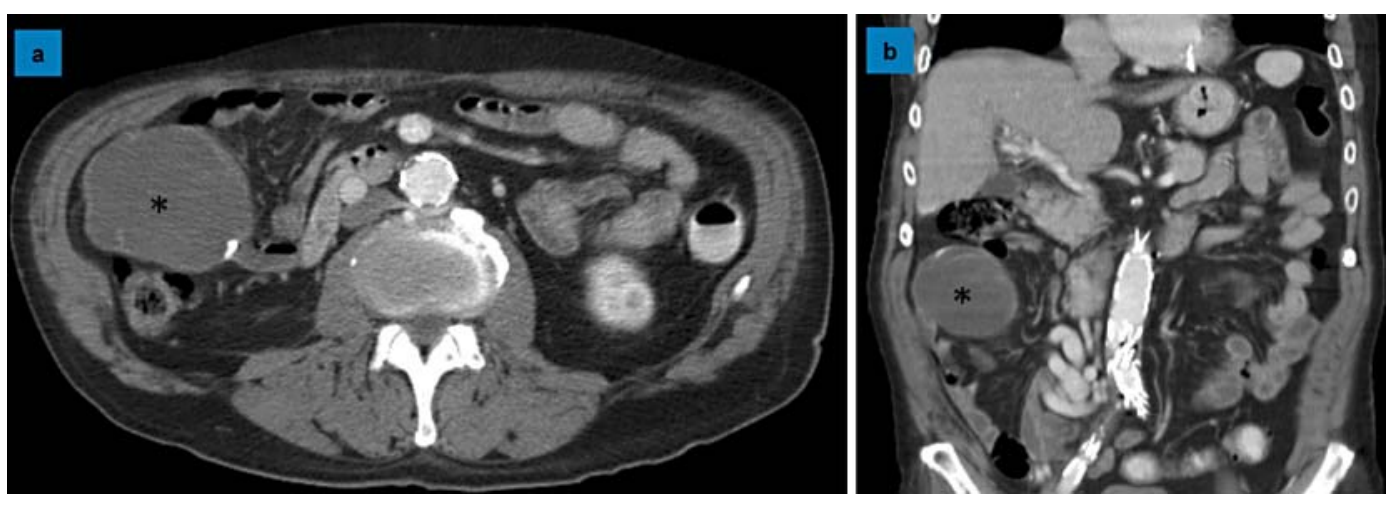

Fig. 1. Large cystic mass in the right abdomen. a Transverse section of the abdominal CT scan showing a $7-\mathrm{cm}$ cystic tumor (asterisk) of the appendix with local calcification of the cyst wall. b Coronal view of the abdominal CT scan showing the same cystic tumor (asterisk) with inhomogeneous uptake of contrast medium.

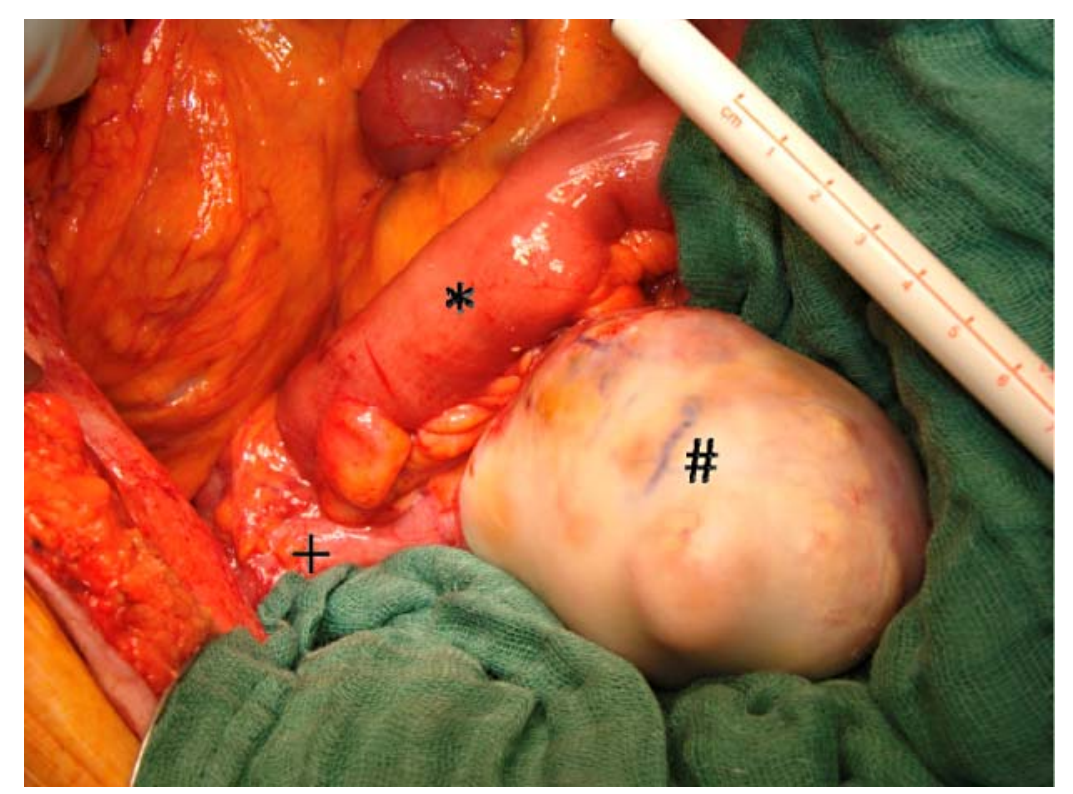

Fig. 2. Intraoperative finding. 7-cm nodulated mass with glossy, white appearance, firm in consistency and mobile except for attachment to the cecum. ${ }^{*}=$ Ileum, $\#=$ tumor, $+=$ cecum. 


\begin{tabular}{r|l|l|l}
$\begin{array}{r}\text { Case Reports in } \\
\text { Gastroenterology }\end{array}$ & $\begin{array}{l}\text { Case Rep Gastroenterol 2011;5:516-522 } \\
\text { DOI: 10.1159/000331438 }\end{array}$ & $\begin{array}{l}\text { Published online: } \\
\text { September 3, 2011 }\end{array}$ & $\begin{array}{l}\text { ○ 2011 S. Karger AG, Basel } \\
\text { ISSN 1662-0631 } \\
\text { www.karger.com/crg }\end{array}$ \\
\hline
\end{tabular}
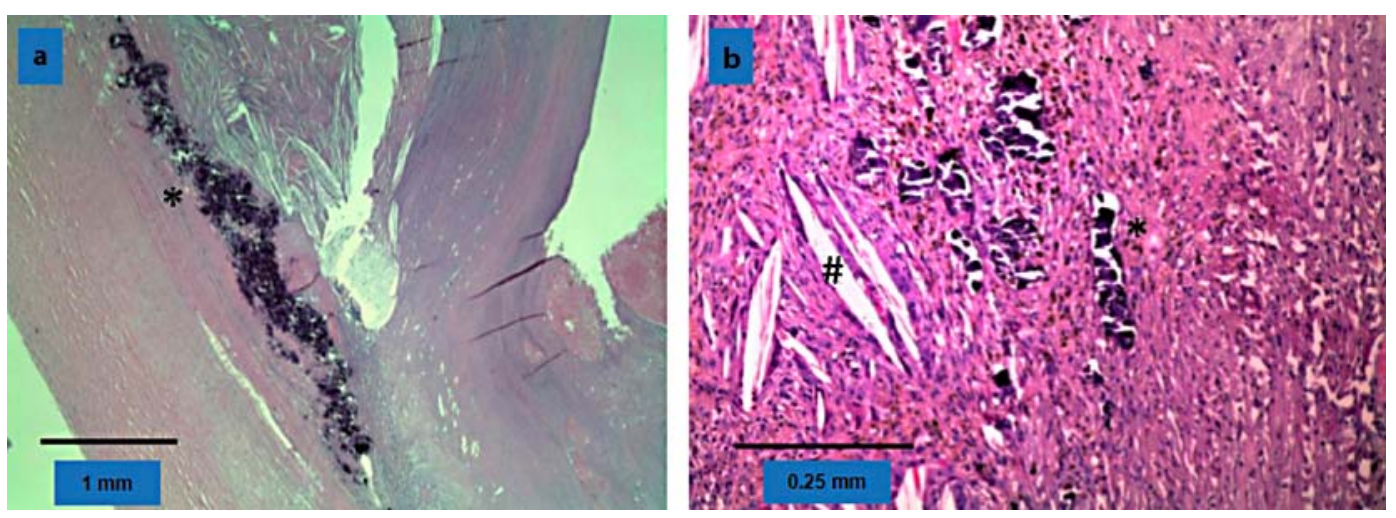

Fig. 3. Histology. a Appendix filled with mucus. At the edge dystrophic mineralisation (asterisk). Little inflammatory reaction and no perforation of the wall. $\mathbf{b}$ Inflammatory reaction with cholesterol granulomas (sharp), dystrophic mineralisation (asterisk) and fibrosis.

\section{References}

1 Bilimoria KY BD, Wayne JD, Ko CY, Bennett CL, Talamonti MS: Small bowel cancer in the United States: changes in epidemiology, treatment, and survival over the last 20 years. Ann Surg 2009;249:63-71.

-2 Sauer R, Becker H, Hohenberger W, Rödel C, Wittekind C, Fietkau R, Martus P, Tschmelitsch J, Hager E, Hess CF, Karstens JH, Liersch T, Schmidberger H, Raab R, German Rectal Cancer Study Group: Preoperative versus postoperative chemoradiotherapy for rectal cancer. N Engl J Med 2004;351:1731-1740.

-3 Glimelius B, Oliveira J, ESMO Guidelines Working Group: Rectal cancer: ESMO clinical recommendations for diagnosis, treatment and follow-up. Ann Oncol 2009;20:iv54-iv56.

4 Qizilbash AH: Mucoceles of the appendix. Their relationship to hyperplastic polyps, mucinous cystadenomas, and cystadenocarcinomas. Arch Pathol 1975;99:548-555.

-5 Hatzaras I, Palesty JA, Abir F, Sullivan P, Kozol RA, Dudrick SJ, Longo WE: Small-bowel tumors: epidemiologic and clinical characteristics of 1,260 cases from the Connecticut tumor registry. Arch Surg 2007;142:229-235.

6 Rokitansky CF: A Manual of Pathological Anatomy. Philadelphia, Blanchard \& Lea, 1855, vol 2.

7 Sugarbaker PH: Epithelial appendiceal neoplasms. Cancer J 2009;15:225-235.

$D_{8}$ Higa E, Rosai J, Pizzimbono CA, Wise L: Mucosal hyperplasia, mucinous cystadenoma, and mucinous cystadenocarcinoma of the appendix. A re-evaluation of appendiceal 'Mucocele'. Cancer 1973;32:1525-1541.

-9 Akbulut S, Tas M, Sogutcu N, Arikanoglu Z, Basbug M, Ulku A, Semur H, Yagmur Y: Unusual histopathological findings in appendectomy specimens: a retrospective analysis and literature review. World J Gastroenterol 2011;17:1961-1970.

$>10$ Bennett GL TT, Macari M, Cho KC, Babb JS: CT diagnosis of mucocele of the appendix in patients with acute appendicitis. AJR Am J Roentgenol 2009;192:103-110.

11 Marudanayagam R, Williams GT, Rees BI: Review of the pathological results of 2,660 appendicectomy specimens. J Gastroenterol 2006;41:745-749.

-12 Ruiz-Tovar J, Teruel DG, Castineiras VM, Dehesa AS, Quindos PL, Molina EM: Mucocele of the appendix. World J Surg 2007;31:542-548.

-13 Smeenk RM, van Velthuysen ML, Verwaal VJ, Zoetmulder FA: Appendiceal neoplasms and pseudomyxoma peritonei: a population based study. Eur J Surg Oncol 2008;34:196-201.

$\checkmark 14$ Landen S, Bertrand C, Maddern GJ, Herman D, Pourbaix A, de Neve A, Schmitz A: Appendiceal mucoceles and pseudomyxoma peritonei. Surg Gynecol Obstet 1992;175:401-404.

15 Zanati SA, Martin JA, Baker JP, Streutker CJ, Marcon NE: Colonoscopic diagnosis of mucocele of the appendix. Gastrointest Endosc 2005;62:452-456.

16 Rampone B, Roviello F, Marrelli D, Pinto E: Giant appendiceal mucocele: report of a case and brief review. World J Gastroenterol 2005;11:4761-4763. 
17 Gillion JF, Franco D, Chapuis O, Serpeau D, Convard JP, Julles MC, Balaton A, Karkouche B, Capelle P, Parmentier T, Chollet JM, Thillois JM, Berthelot G: [Appendiceal mucoceles, pseudomyxoma peritonei and appendiceal mucinous neoplasms: update on the contribution of imaging to choice of surgical approach]. J Chir (Paris) 2009;146:150-166.

18 Misdraji J, Yantiss RK, Graeme-Cook FM, Balis UJ, Young RH: Appendiceal mucinous neoplasms: a clinicopathologic analysis of 107 cases. Am J Surg Pathol 2003;27:1089-1103.

19 Dhage-Ivatury S, Sugarbaker PH: Update on the surgical approach to mucocele of the appendix. J Am Coll Surg 2006;202:680-684.

20 Gonzalez-Moreno S, Sugarbaker PH: Right hemicolectomy does not confer a survival advantage in patients with mucinous carcinoma of the appendix and peritoneal seeding. Br J Surg 2004;91:304-311.

C. Kim-Fuchs and Y. Chittazhathu Kurian Kuruvilla contributed equally to this work. 